\title{
IMPROVING ELECTRICAL POWER QUALITY IN DISTRIBUTION NETWORKS USING A UNIFIED POWER QUALITY CONDITIONER (UPQC) CONTROLLED BY AN ADAPTIVE HYSTERESIS BAND
}

\section{MARAH MARIAM and HASSAN KENJRAWY}

Department of Electrical Power Engineering

Tishreen University

2230 Lattakia

Syria

e-mail: marah.mariam@tishreen.edu.sy

hassan.a.kenjrawy@gmail.com

\begin{abstract}
Recently the use of sensitive electronic devices has increased, and the quality of energy has become an important factor in electrical power systems, where disturbances occurring in the network (harmonics, swell, voltage sag, etc.) affect consumers and lead to technical-economic damages. One of the most prominent solutions to address energy quality problems is the UPQC (Unified Power Quality Conditioner).
\end{abstract}

Keywords and phrases: unified power quality conditioner, power quality, adaptive hysteresis band, total distortion factor THD\%.

Received March 18, 2021; Revised March 25, 2021

(C) 2021 Scientific Advances Publishers

This work is licensed under the Creative Commons Attribution International License (CC BY 3.0).

http://creativecommons.org/licenses/by/3.0/deed.en_US

Open Access (cc) (9)


In this paper, the unified power quality conditioner used to improve the electrical power quality in the distribution networks was discussed, where the Park transformations are used to obtain the required reference signals, and also the use of adaptive hysteresis band to generate the electronic switch pulses in both serial and shunt switches, where the pulse width is determined by dependence on fuzzy logic.

The studied system was validated by simulating different distortion cases and comparing the results when using the Sinusoidal Pulse Width Modulation (SPWM) to control the two switches. The results showed improvement in the electrical power quality through the use of an adaptive hysteresis band controller, and that appeared by reducing the total distortion factor (THD\%), which resulted in improving the shape of both the voltage and current waveforms.

\section{Introduction}

Industrial and technical progress has led to the increasing use of advanced electronic equipment, but the operation of these equipment has led to the emergence of many problems in the electrical network, including the emergence of higher harmonics, and thus the deformation of the input voltage waveform. Likewise, the transient cases that occur in the electrical network during the separation and connection of large loads, and the starting of high-power motors, are some of the causes of disturbances in the electrical network, such as voltage sag and swell that negatively affect other loads connected to the network. On the other hand, the use of electrical and electronic equipment sensitive to the quality of electric energy has led to restrictions on the quality of energy provided by the network [1].

The methodology for improving energy quality based on electronic devices is an effective solution to energy quality problems. One of the best solutions to improve electrical power quality is the use of a UPQC unified power quality conditioner that combines the properties of serial and shunt active filters together [1], [2]. 
Previously, many traditional methods were used to overcome power quality problems; like static capacitors to compensate for the reactive power in the network, also used induction reactors to consume the reactive power in the network during the low load period, and also used Thyristor Switched Capacitor (TCS) \& Thyristor Controlled Reactor (TCR) and Static VAR compensators (TCR) Compensator, which gave more flexibility to control the inductive power compensation [3]. Passive filters were used to eliminate the harmonics, but these methods suffer from many disadvantages, such as the magnitude of the size, the possibility of resonant circuits occurrences, and most importantly, the fixed compensation that limits the possibility of performing their functions [4].

Active filters have also been used that are more flexible than inactive filters and are smaller in size, and provide greater control capacity [5]. Shunt Active Filters that are connected in parallel with the load are used to overcome current power quality problems such as harmonics and to compensate reactive power [6]. Series Active Filters, which are connected in series with the load, is used to overcome voltage-related power quality problems (sags, voltage swell, interruptions, etc.) [7]). Mixed filters (serial - shunt) are used which combine characteristics of serial and shunt filters together to treat voltage and current related power quality problems, called the Unified Power Quality Conditioner (UPQC), which is the most effective filter. 


\section{Unified (Mixed) Power Quality Conditioner (UPQC)}

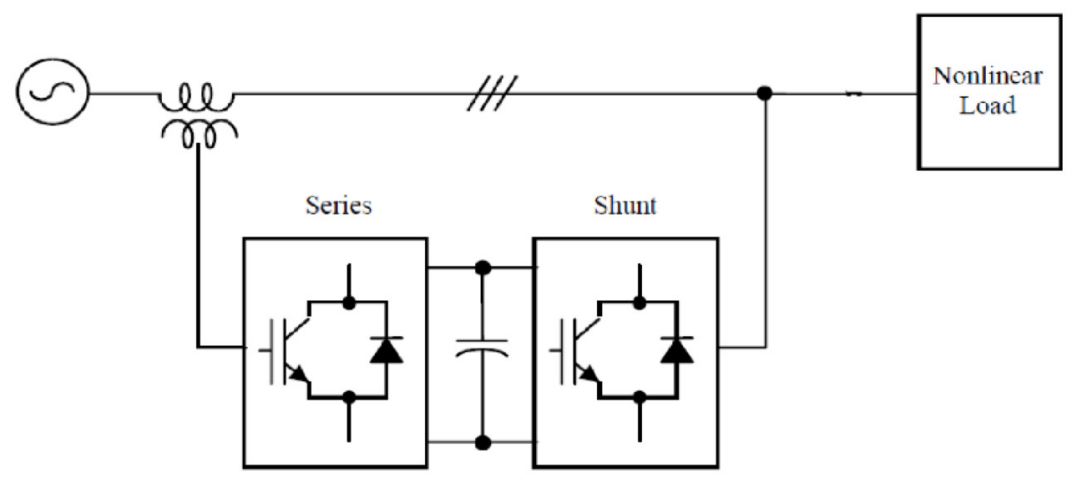

Figure 1. Unified power quality conditioner (UPQC).

It is one of the best solutions to deal with power quality problems. It consists of two switches, one connected in series and the other connected in parallel with the load and they share a common DC link. Figure 1 shows the most common structure of UPQC - there are several possible connection methods for UPQC which differ according to the desired function of UPQC [8].

$\mathrm{UPQC}$ is divided into:

- Capacitor voltage regulation;

- Control of shunt and serial switches.

\subsection{Capacitor voltage regulation}

Many methods have been used to regulate the capacitor voltage, such as proportional- integral controller PI, and proportional integral differential controller (PID), but they need a linear mathematical model, and according to studies, PI is better than PID because the differential element is very sensitive to measuring noise [9], and it fails to regulate capacitor voltage at dynamic operating conditions. Artificial intelligence methods, such as neural networks [10] and fuzzy logic [11] have also been used. These methods are characterized by rapid response, and they do not require mathematical models [12]. 
We will use fuzzy logic to regulate capacitor voltage because it performs better than a PI controller and does not require a mathematical model.

Seven fuzzy groups represented by organic functions of the trigonometric type were selected to characterize the output as shown in Table 1.

Table 1. Fuzzy rules for the fog controller used to control capacitor voltage

\begin{tabular}{|c|c|c|c|c|c|c|c|}
\hline e & NB & NM & NS & ZE & PS & PM & PB \\
\hline NB & NB & NB & NB & NB & NM & NS & ZE \\
\hline NM & NB & NB & NM & NM & NS & ZE & PS \\
\hline NS & NB & NM & NS & NS & ZE & PS & PM \\
\hline ZE & NB & NM & NS & ZE & PS & PM & PB \\
\hline PS & NM & NS & ZE & PS & PS & PM & PB \\
\hline PM & NS & ZE & PS & PM & PM & PB & PB \\
\hline PB & ZE & PS & PM & PB & PB & PB & PB \\
\hline
\end{tabular}

\subsection{Switch control (reference signals generation)}

There are several methods used to generate reference signals (generation of reference voltages for the serial switches, generation of reference currents of the shunt switches), some of which depend on the frequency field such as the fast Fourier transformation and the discontinuous Fourier transformation. However, considerations regarding performing the calculations (long time and large memory required) limited their use [13]. Some of them depend on the time domain, such as the theory of instantaneous active and reactive power $(p \& q)$, and the synchronous reference frame theory (SRF), as these two methods are characterized by the basic components of the active and reactive power components related to $p \& q$, And the primary voltage or current component of the SRF are continuous quantities that can be easily 
extracted with suitable filters. However, the theory $p$ - $q$ cannot function properly if the voltages are unbalanced. The unbalance of voltage leads to failure of control, requiring additional control loops, which complicates the control system [14].

\subsubsection{Serial switches control}

We will use the SRF theory to generate reference voltages, whereby the single band method we generate three amplitude rays of $1 \mathrm{pu}$ each with an angle of $120^{\circ}$ from each other as shown in Equations (0), where the initial voltage angle $(\theta)$ is obtained in coordinates $(d-q)$, and obtained through a Phase Locked Loop (PLL) [15].

$$
\begin{aligned}
& V_{a}=\sin (\omega t+\theta) \\
& V_{b}=\sin \left(\omega t+\theta-\frac{2 \pi}{3}\right), \\
& V_{b}=\sin \left(\omega t+\theta+\frac{2 \pi}{3}\right) .
\end{aligned}
$$

Figure 2 shows the control diagram for the serial active filter.

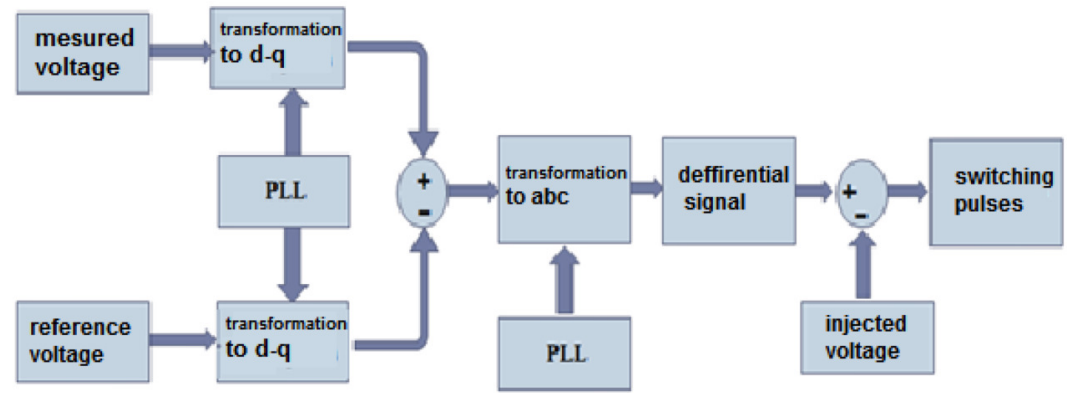

Figure 2. The control diagram for the serial active filter. 
The conversion from the $a b c$ coordinates to the $d-q$ coordinate was carried out using the park transformation depending on the Equation (1).

$$
\left[\begin{array}{l}
u_{d} \\
u_{q} \\
u_{0}
\end{array}\right]=\frac{2}{3}\left[\begin{array}{ccc}
\cos (\theta) & \cos \left(\theta-\frac{2 \pi}{3}\right) & \cos \left(\theta+\frac{2 \pi}{3}\right) \\
-\sin (\theta) & -\sin \left(\theta-\frac{2 \pi}{3}\right) & -\sin \left(\theta+\frac{2 \pi}{3}\right) \\
\frac{1}{2} & \frac{1}{2} & \frac{1}{2}
\end{array}\right]\left[\begin{array}{l}
u_{a} \\
u_{b} \\
u_{c}
\end{array}\right] .
$$

Then the $d-q$ compounds are filtered, and the $d-q$ coordinate is converted to the $a b c$ coordinate using the reverse park transformation shown by Equation (2).

$$
\left[\begin{array}{l}
u_{a} \\
u_{b} \\
u_{c}
\end{array}\right]=\left[\begin{array}{ccc}
\cos (\theta) & -\sin (\theta) & 1 \\
\cos \left(\theta-\frac{2 \pi}{3}\right) & -\sin \left(\theta-\frac{2 \pi}{3}\right) & 1 \\
\cos \left(\theta+\frac{2 \pi}{3}\right) & -\sin \left(\theta+\frac{2 \pi}{3}\right) & 1
\end{array}\right]\left[\begin{array}{l}
u_{d} \\
u_{q} \\
u_{0}
\end{array}\right]
$$

\subsubsection{Shunt switch control}

The shunt active filter handles current power quality problems and compensates for the reactive power. The reference signals required for the operation of the filter are generated through Park transformations where the transition is made from $(\mathrm{ABC})$ coordinates to the coordinate $d$ - $q$, where the initial voltage angle is obtained through the Phase Locked Loop (PLL) as shown in Figure 3, and then starts the process of filtering $d$ - $q$ compounds using a suitable filter, and finally, through reverse Park transformations the reference signals are obtained by the transition from the $d-q$ coordinate to the $\mathrm{ABC}$ coordinate. 


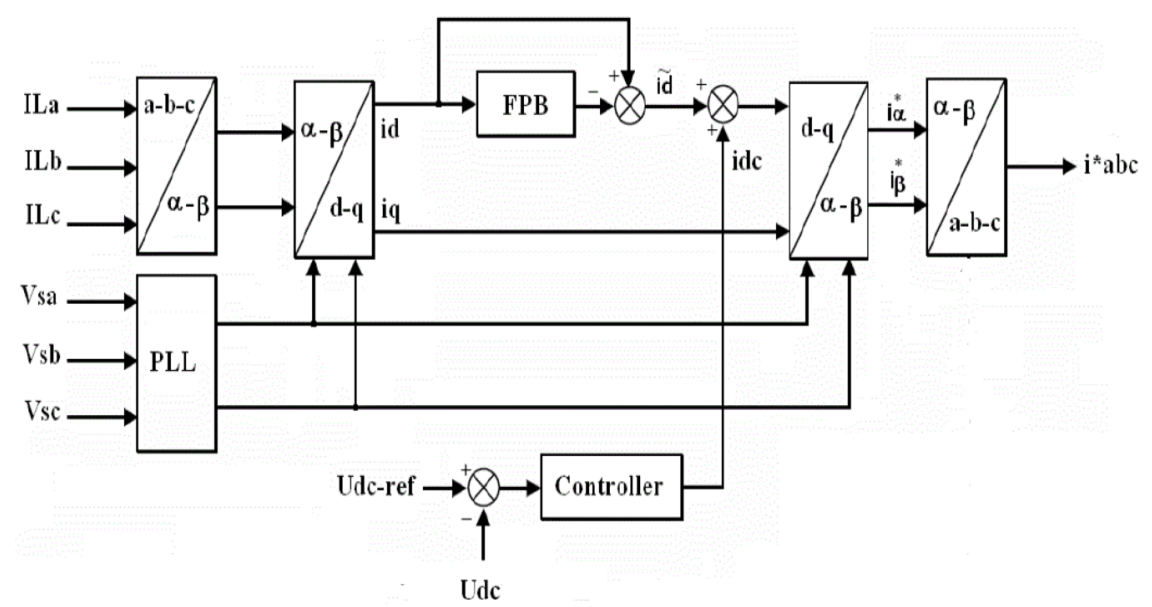

Figure 3. The control diagram for the shunt active filter.

\subsubsection{Pulse generation system}

There are several techniques for generating pulses for electronic switches, including linear techniques (PWM-SPWM-SVPWM), non-linear techniques, neural networks, fuzzy logic, and the Hysteresis Band (HB) delay.

In this paper, we will present the Adaptive Hysteresis Band (AHB) to control the output of the switches in the UPQC, which is characterized by a fast response, accuracy in tracing the signal, and less ripple of the wave. It is worth noting that the bandwidth is variable and can be calculated mathematically or through artificial intelligence methods, where a comparison is made between the source voltage (Vs) and the reference signal differential (ref), where the resulting signal is fed to the fuzzy logic controller, thus the output of this controller is the bandwidth, as well. As shown in Figure 4. The results will be compared when using the (SPWM) system that depends on comparing the reference signal (Vref, Iref) with the sawtooth signal (carrier signal) (Vcar, Icar) to generate control impulses for the electronic switches as shown in Figure 5(a). 


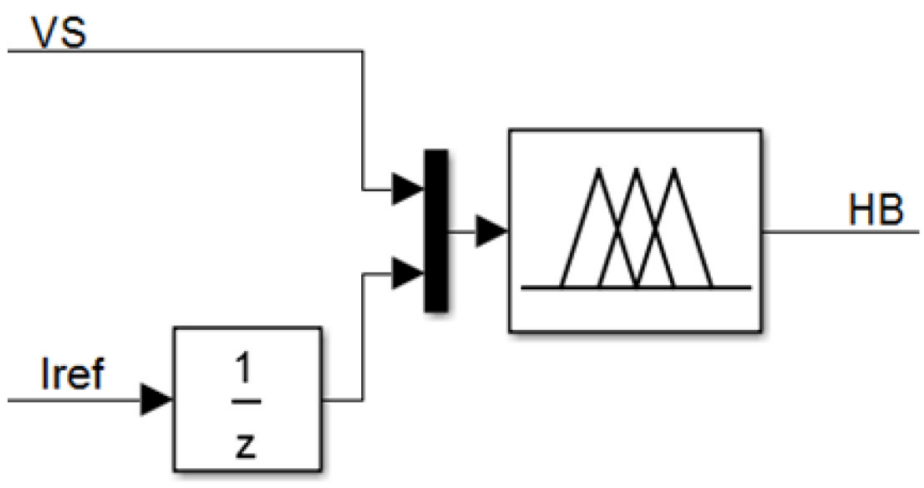

(a)

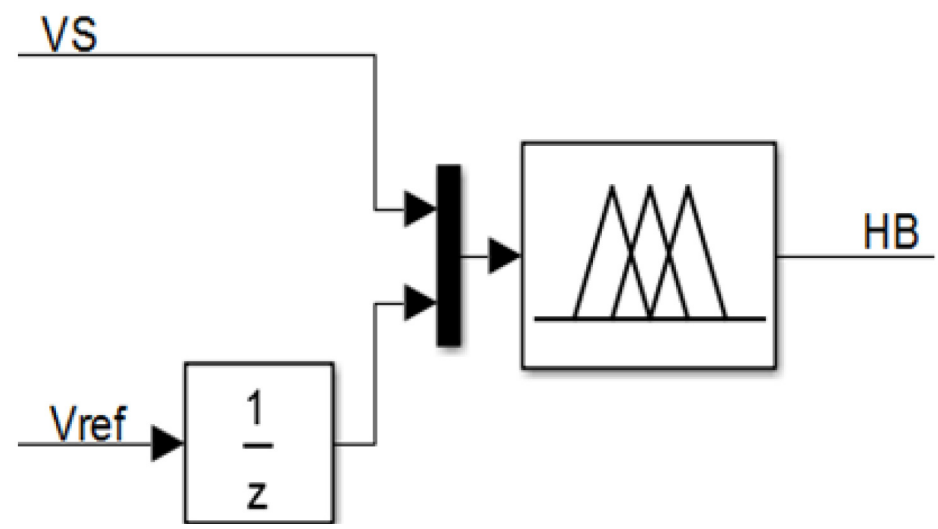

(b)

Figure 4. Calculation of the adaptive hysteresis band width (HB) using fuzzy logic (a) for current (b) for voltage.

The adaptive Hysteresis Band method is shown in Figure 5(b) where pulses are obtained for both the voltage and current switches by comparing the actual value with the reference signal, where the beamwidth is variable (2HB), and it was calculated through fuzzy logic. 

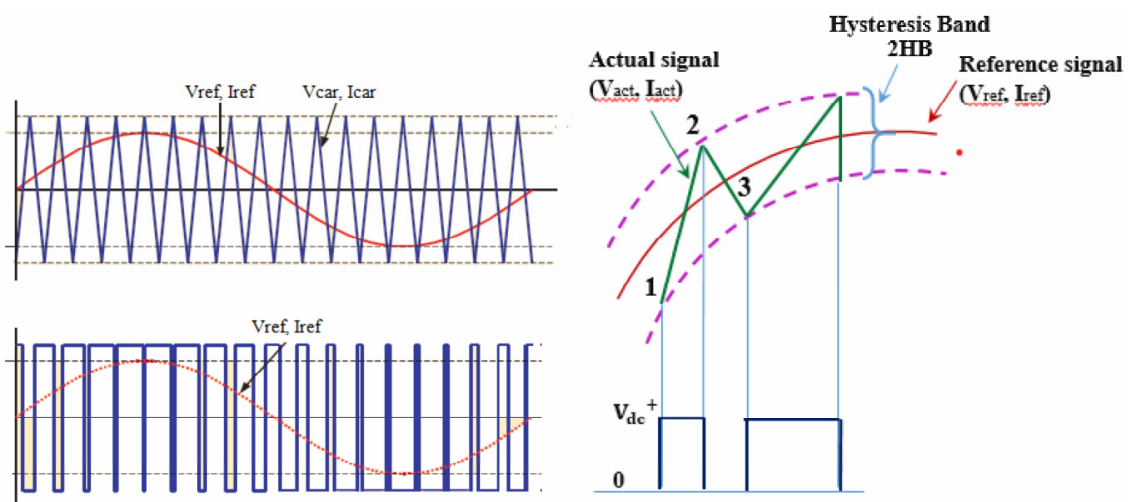

Figure 5. Pulse generation (a) using SPWM, (b) using an adaptive Hysteresis Band.

The bandwidth was determined by fuzzy logic. Five blurry groups represented by organic functions of the triangular type were chosen to characterize the output as shown in Table 2.

Table 2. Fuzzy groups to determine the bandwidth

\begin{tabular}{|c|c|c|c|c|c|}
\hline$\frac{d \imath_{c}}{d t}$ & NL & NM & $\mathrm{ZE}$ & $\mathbf{P M}$ & PL \\
\hline NL & PVS & PS & PS & $\mathrm{PM}$ & $\mathrm{PM}$ \\
\hline NM & PS & PS & PS & $\mathrm{PM}$ & $\mathrm{PM}$ \\
\hline $\mathbf{Z E}$ & PL & PL & PVL & PL & PL \\
\hline PM & $\mathrm{PM}$ & $\mathrm{PM}$ & PS & PS & PS \\
\hline PL & $\mathrm{PM}$ & $\mathrm{PM}$ & PS & PS & PVS \\
\hline
\end{tabular}

The voltage bandwidth was similarly determined by fuzzy logic by selecting five fuzzy groups represented by organic functions of the triangular type to characterize the output of the serial filter. 


\section{Simulation and Modelling the Studied System}

Figure 6 shows a simulation of the studied system, where both the serial and shunt filters were simulated and combined with each other through the DC link.
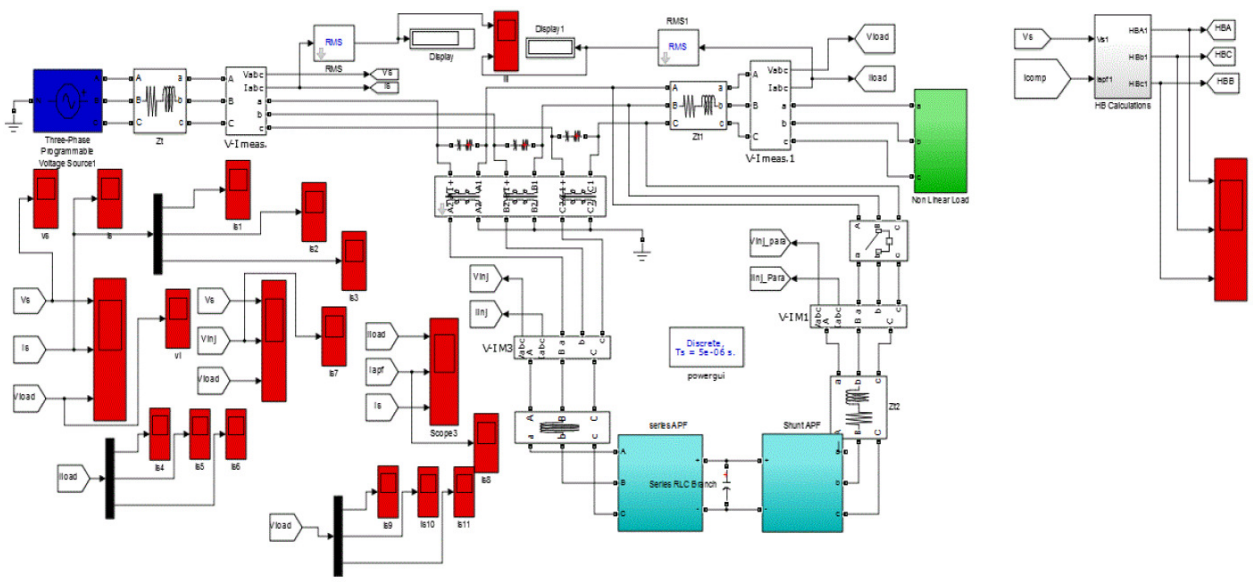

Figure 6. Simulation of the studied system.

Table 3 shows the values of the elements of the used model.

Table 3. The nominal values of the elements in the system

\begin{tabular}{|r|r|}
\hline $380 \mathrm{~V}$ & Liner voltage \\
\hline $219.3 \mathrm{~V}$ & Phase voltage \\
\hline $310.2 \mathrm{~V}$ & Maximum value of the phase voltage \\
\hline $50 \mathrm{~Hz}$ & Frequency \\
\hline $\mathrm{L}=30 \mathrm{mh} ، \mathrm{R}=15 \Omega$ & Load resistance \\
\hline $1: 1$ & Transformer conversion ratio \\
\hline $800 \mathrm{~V}$ & DC voltage \\
\hline $\mathrm{L}_{\mathrm{L}}=10 \mu \mathrm{h} \mathrm{R}_{\mathrm{L}}=0.1 \Omega$ & Line resistance \\
\hline
\end{tabular}




\section{Simulation Results}

Several cases of voltage and current disturbances were performed and values of the total distortion factor were determined for both voltage and current waveforms.

\subsection{Voltage sag (the voltage value drops to $60 \%$ of its nominal value)}

Figure 7 shows the input voltage waveform in the event that it falls $40 \%$ of its nominal value, where the value of the total distortion factor of the voltage is $15.15 \%$.

a

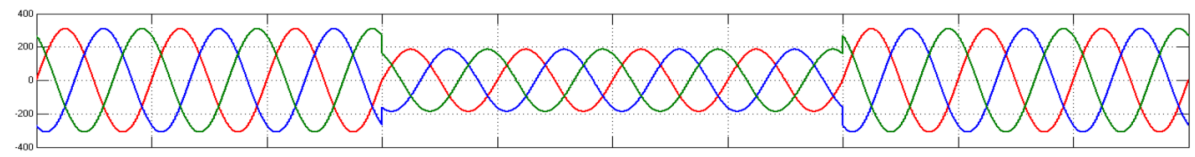

b

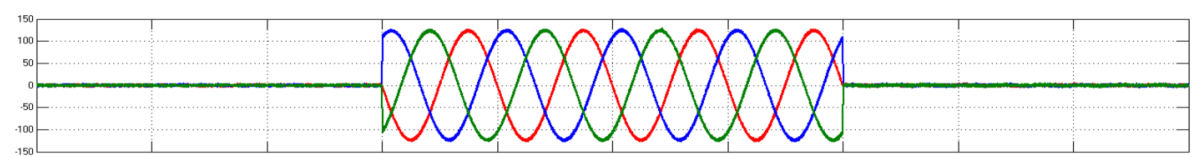

C

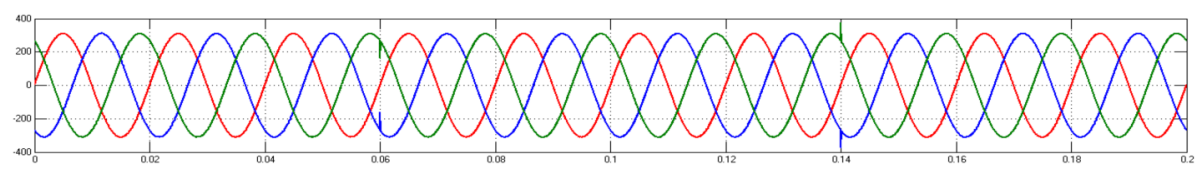

Figure 7. Voltage sag (a) input voltage, (b) injected voltage, and (c) load voltage.

By conducting a Fourier transformation to calculate the THD\% for all phases before and after using the serial active filter as shown in Table 4, which shows the comparison of the value of the total distortion factor when using the Fourier transformation for all phases when using the serial active filter led by AHB, SPWM to compensate for the voltage sag. 
IMPROVING ELECTRICAL POWER QUALITY ...

Table 4. The THD\% value in case of voltage sag

\begin{tabular}{|c|c|c|c|}
\hline Phase & Source THD\% & $\begin{array}{c}\text { THD\% when SPWM } \\
\text { is used }\end{array}$ & $\begin{array}{c}\text { THD\% when AHB } \\
\text { is used }\end{array}$ \\
\hline $\mathrm{a}$ & $15.15 \%$ & $1.92 \%$ & $1.63 \%$ \\
\hline $\mathrm{b}$ & $15.5 \%$ & $1.96 \%$ & $1.69 \%$ \\
\hline $\mathrm{c}$ & $15.32 \%$ & $1.97 \%$ & $1.7 \%$ \\
\hline
\end{tabular}

We notice from the previous table the large value of the total distortion factor before entering the filter, and its decrease to a small value after entering the filter, which shows the importance and effective role of the effective serial filter in general and the quality of the AHB delay beam controller in particular in treating the voltage sag and eliminating its effects.

\subsection{Voltage swell (increasing the voltage value to $140 \%$ of its nominal value)}

Figure 8 shows the input voltage waveform if it increases by $40 \%$ of its nominal value, where the total distortion factor value is $10.97 \%$.

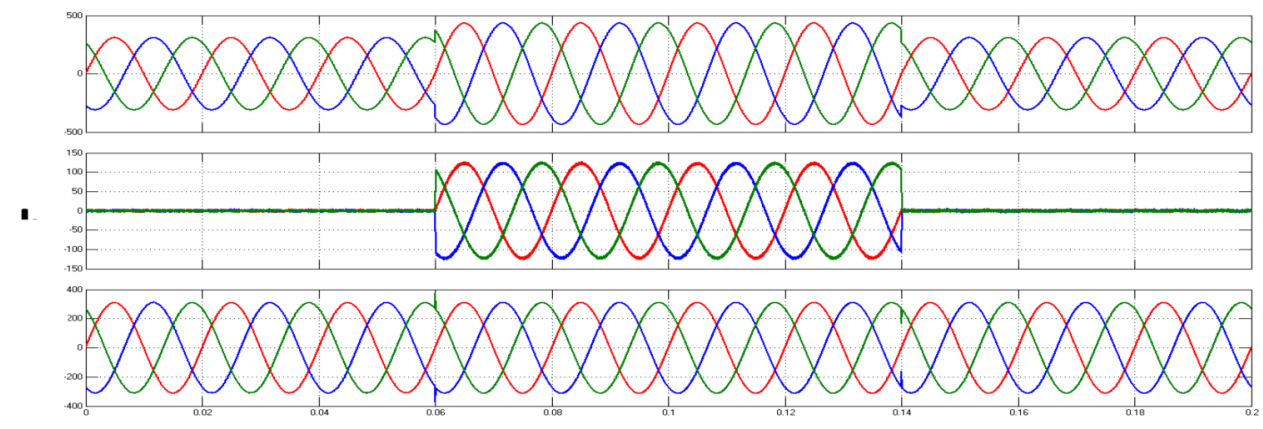

Figure 8. Voltage swell (a) input voltage, (b) injected voltage, and (c) load voltage.

Table 5 shows a comparison of the total distortion factor value when using a Fourier transformation for all phases when using the serial active filter driven by SPWM, AHB to compensate for voltage swell. 
Table 5. The THD\% value in the case of voltage swell

\begin{tabular}{|c|c|c|c|}
\hline Phase & Source THD\% & $\begin{array}{c}\text { THD\% when SPWM } \\
\text { is used }\end{array}$ & $\begin{array}{c}\text { THD\% when AHB } \\
\text { is used }\end{array}$ \\
\hline $\mathrm{a}$ & $\% 10.97$ & $1.75 \%$ & $1.29 \%$ \\
\hline $\mathrm{b}$ & $\% 11.02$ & $1.76 \%$ & $1.31 \%$ \\
\hline $\mathrm{c}$ & $10.98 \%$ & $1.78 \%$ & $1.32 \%$ \\
\hline
\end{tabular}

Thus, through the low values of THD\%, we conclude the ability of the serial active filter in general and the serial active filter led by AHB in particular to treat the voltage swell that may occur in the network.

\subsection{Treatment of current harmonic}

Given that the load is non-linear, the harmonics will appear in the current waveform, Figure 9 shows the current waveform before and after the current harmonics' compensation, where the harmonics are compensated by the active filter, where the shunt filter is entered at a time of 0.08 sec.

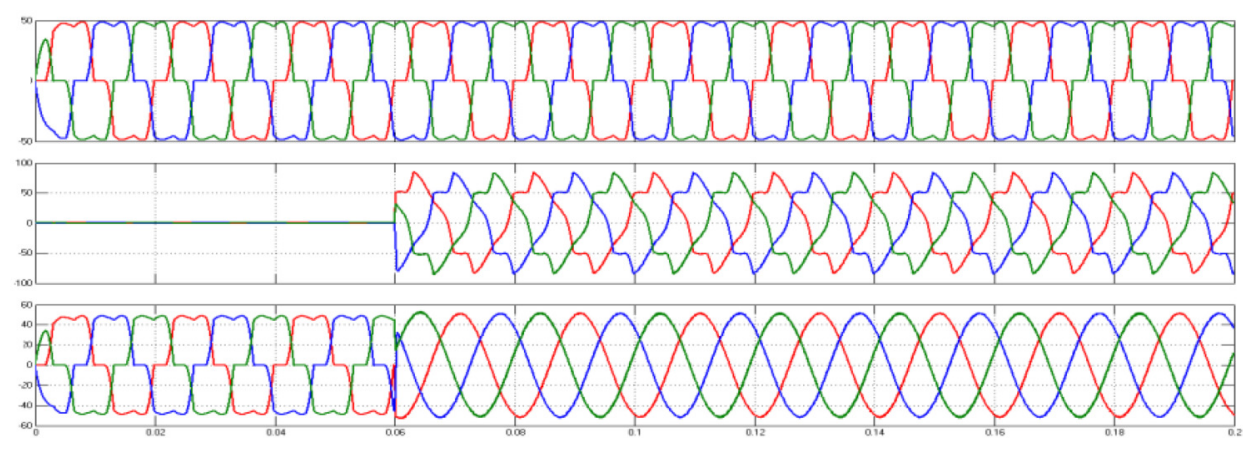

Figure 9. Current waveforms before and after compensation (a) load current, (b) filter current, and (c) input current.

By conducting a Fourier analysis of the three phases to calculate the total distortion factor THD\% in the two cases of the filter (two-level and multi-level) as shown in Table 6. 
Table 6. Total distortion factor of the two-level and multi-level filter in case of balanced loading

\begin{tabular}{|c|c|c|c|}
\hline Phase & Source THD\% & $\begin{array}{c}\text { THD\% when SPWM } \\
\text { is used }\end{array}$ & $\begin{array}{c}\text { THD\% when AHB } \\
\text { is used }\end{array}$ \\
\hline $\mathrm{a}$ & $20.97 \%$ & $3.72 \%$ & $2.49 \%$ \\
\hline $\mathrm{b}$ & $23.1 \%$ & $3.76 \%$ & $2.5 \%$ \\
\hline $\mathrm{c}$ & $24.04 \%$ & $3.77 \%$ & $2.5 \%$ \\
\hline
\end{tabular}

\subsection{Treating the unbalanced loading problem}

When loading the first and second phases with a reactive load, the load will draw from the source unequal currents between the three phases. Figure 10 shows the current waveforms in the case of unbalanced loading between the three phases.

a

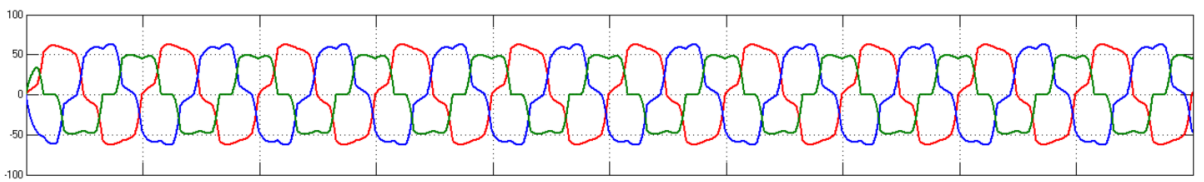

b

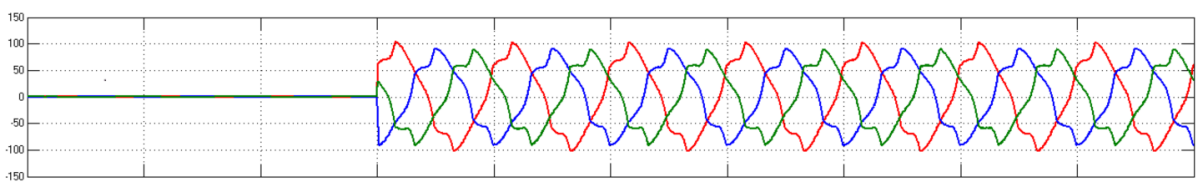

c

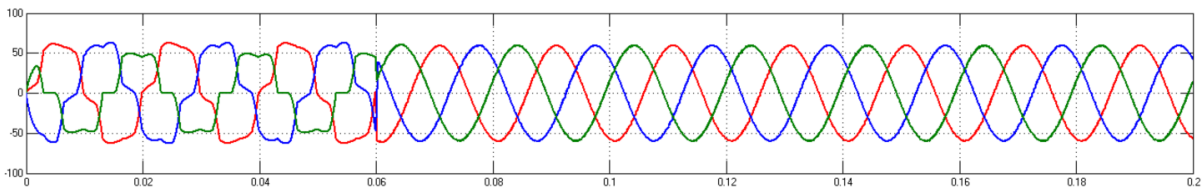

Figure 10. Current waveforms (a) input current, (b) shunt filter current, and (c) load current.

The two previous figures show the ability of the shunt active filter to treat unbalanced disturbances as well. We notice a significant decrease in the total distortion factor from $15.2 \%$ (before entering the filter) to $0.43 \%$ after entering the filter. 
By conducting a Fourier analysis of the three phases to calculate the total distortion factor THD in both cases of the filter when using the serial active filter led by AHB, SPWM to compensate the harmonics of current as shown in Table 7.

Table 7. Total distortion factor of the two-level and multi-level filter in the case of unbalanced loading

\begin{tabular}{|c|c|c|c|}
\hline Phase & Source THD\% & $\begin{array}{c}\text { THD\% when SPWM } \\
\text { is used }\end{array}$ & $\begin{array}{c}\text { THD\% when AHB } \\
\text { is used }\end{array}$ \\
\hline $\mathrm{a}$ & $15.2 \%$ & $2.89 \%$ & $2.43 \%$ \\
\hline $\mathrm{b}$ & $15.22 \%$ & $2.9 \%$ & $2.44 \%$ \\
\hline $\mathrm{c}$ & $18.06 \%$ & $2.94 \%$ & $2.43 \%$ \\
\hline
\end{tabular}

\subsection{Treating voltage harmonics}

When there are harmonics in the input voltage waveforms as shown in Figure 11, where the figure shows both the input voltage and the injected voltage from the series switch and the voltage connected to the load.

ב

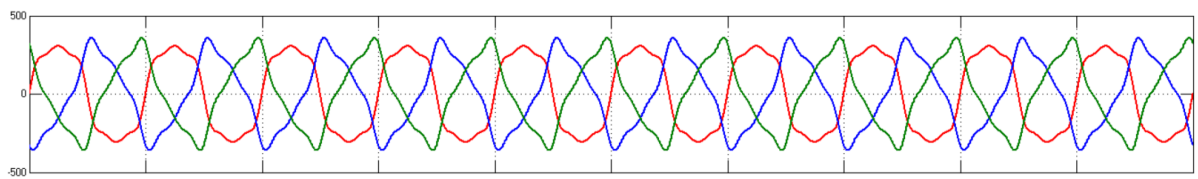

.

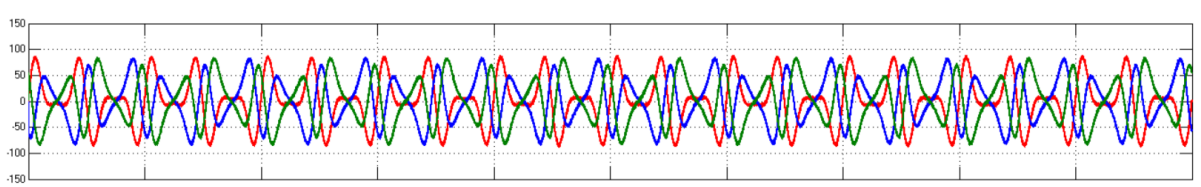

$\boldsymbol{r}$

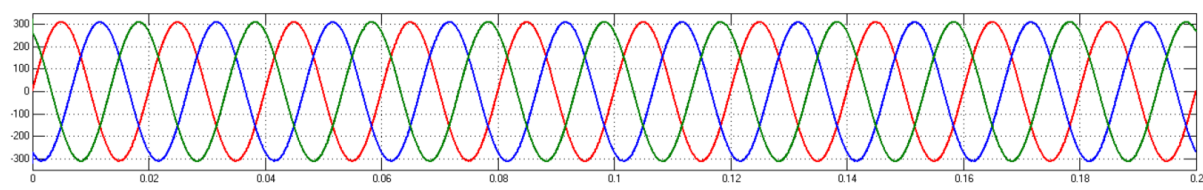

Figure 11. (a) The input voltage, (b) the injected voltage, and (c) the load voltage. 
By conducting a Fourier transformation of phase voltage, we note that the total distortion factor decreased from $17.67 \%$ to $0.6 \%$. Table 8 shows the comparison of the total distortion factor value when using a Fourier transformation for all phases when using SPWM guided by AHB, UPQC for processing voltage harmonics.

Table 8. The THD\% value in the case of voltage harmonics compensation

\begin{tabular}{|c|c|c|c|}
\hline Phase & Source THD\% & $\begin{array}{c}\text { THD\% when SPWM } \\
\text { is used }\end{array}$ & $\begin{array}{c}\text { THD\% when AHB } \\
\text { is used }\end{array}$ \\
\hline $\mathrm{a}$ & $17.67 \%$ & $2.11 \%$ & $1.55 \%$ \\
\hline $\mathrm{b}$ & $17.69 \%$ & $2.14 \%$ & $1.58 \%$ \\
\hline $\mathrm{c}$ & $17.7 \%$ & $2.12 \%$ & $1.56 \%$ \\
\hline
\end{tabular}

Thus, through the low values of the total distortion factor, we have seen the ability of UPQC in general and UPQC led by AHB in particular to process the voltage harmonics that may occur in the network, thus eliminating the harmful effects of the presence of harmonics and the technical and economic problems they cause on consumers.

\section{The Results Discussion}

(1) A Unified Power Quality Conditioner (UPQC) has been proposed, where each part of the switches works separately to compensate for voltage (serial) and current (shunt) problems.

(2) The proposed system was simulated and different perturbations were studied before and after compensation to verify the effectiveness of the proposed Unified Power Quality Conditioner.

The results showed that the voltage and current problems could be overcome by using the Unified Power Quality Conditioner. Through Park transformation, accurate reference signals were extracted. Also, the Adaptive Hysteresis Band using fuzzy logic had good results for the generation of the electronic switches pulses. It was also observed that the 
total distortion factor of both the current and the voltage waveforms decreased to less than $3 \%$. This positively affects the shape of the input current waveforms and the load voltage waveforms.

\section{Recommendations}

(1) Use of UPQC to compensate for voltage and current problems in electrical power systems.

(2) Using the proposed system in FACTS systems as advanced compensators through which we can dispense with the traditional compensators TSC and TCR as a distinct compensation device that achieves a lower deformation coefficient.

(3) During periods of instantaneous outage (transient state), higher harmonics can arise that lead to distortion of the output waveforms. Therefore, we recommend multi-level switches or Uninterruptible Power Supplies (UPS) that are in a state of permanent readiness (stand by) to operate during periods of instantaneous outage.

\section{References}

[1] J. P. Sridhar and Dr. R. Prakash, Power quality issues and its mitigation by unified power quality conditioner, ICCTEST, 2017.

DOI: https://doi.org/10.21647/ICCTEST/2017/49081

[2] S. Paramanik, K. Sarker, D. Chatterjee and S. K Goswami, Smart grid power quality improvement using modified UPQC, IEEE Devices for Integrated Circuit, 2019.

DOI: https://doi.org/10.1109/DEVIC.2019.8783704

[3] R. H. Stevens, Standard definitions for the measurement of electric power quantities under sinusoidal, non-sinusoidal, balanced, or unbalanced conditions, Revision of IEEE Std. 1459-2000, IEEE Standard 1459-2010.

DOI: https://doi.org/10.1109/IEEESTD.2010.5439063

[4] A. Chauhan and R. Thakur, Power quality improvement using passive \& active filters, International Journal of Engineering Trends and Technology 36(3) (2016), 130-135.

DOI: https://doi.org/10.14445/22315381/IJETT-V36P225 
[5] Amir A. Imam, R. Sreerama Kumar and Yusuf A. Al-Turki, Modeling and simulation of a PI controlled shunt active power filter for power quality enhancement based on P-Q theory, Electronics 9(4) (2020); Article 637.

DOI: https://doi.org/10.3390/electronics9040637

[6] S. Agarwal, S. Chourasiya and D. K. Palwalia, Performance measure of shunt active power filter applied with intelligent control techniques, Journal of Power Technologies 100(3) (2020), 272-278.

[7] M. Nabipour, M. Razaz, S. Gh. Seifossadat and S. S. Mortazavi, A novel adaptive fuzzy membership function tuning algorithm for robust control of a PV-based dynamic voltage restorer (DVR), Engineering Applications of Artificial Intelligence 53 (2016), 155-175.

DOI: https://doi.org/10.1016/j.engappai.2016.04.007

[8] T. M. Thamizh Thentral, R. Jegatheesan and K. Vijayakumar, Unified power quality conditioner with reduced switch topology for distributed networks, Wireless Networks 27(2) (2019), 909-923.

DOI: https://doi.org/10.1007/s11276-019-02189-y

[9] G. Hailay, Reactive Power Compensation and Harmonic Mitigation in $25 \mathrm{kV}$ AC Railway System using Shunt Active Filter, Addis Ababa University, 2016.

[10] S. Vinnakoti and V. Reddy Kota, Implementation of artificial neural network based controller for a five-level converter based UPQC, Alexandria Engineering Journal 57(3) (2018), 1475-1488.

DOI: https://doi.org/10.1016/j.aej.2017.03.027

[11] K. Dhilleswaramma, K. B. Madhu Sahu and Ch. Krishna Rao, Improved power quality features using fuzzy based UPQC topology for BLDC drive applications, International Journal of Electrical and Electronics Engineering Research 5(1) (2015), 45-58.

[12] S. Chennai, Novel control scheme for unified power quality conditioner based on three-level (NPC) inverter using intelligent systems, 8th International Conference on Modelling, Identification and Control, IEEE, 2017.

DOI: https://doi.org/10.1109/ICMIC.2016.7804192

[13] V. Khadkikar, Enhancing electric power quality using UPQC: A comprehensive overview, IEEE Transactions on Power Electronics 27(5) (2012), 2284-2297.

DOI: https://doi.org/10.1109/TPEL.2011.2172001

[14] B. Gopal, P. K. Murthy and G. N. Sreenivas, A review on UPQC for power quality improvement in distribution system, Global Journal of Researches in Engineering 13(7) (2013), 41-49. 